\title{
棂国pubvet
}

https://doi.org/10.31533/pubvet.v15n03a778.1-8

\section{O órgão de gustação dos cães domésticos (Canis lupus familiaris Linnaeus, 1758)}

\author{
Catia Helena de Almeida Lima Massari ${ }^{1 *} \bullet$, Laleska Barbosa ${ }^{2} \bullet$, Henrique Ribeiro Alves de Resende ${ }^{3 \bullet}$ \\ ${ }^{1}$ Médica Veterinária, Pós-doutoranda no Departamento de Cirurgia, Faculdade de Medicina Veterinária e Zootecnia, Universidade de São \\ Paulo. São Paulo-SP, Brasil. \\ ${ }^{2}$ Estudante de graduação em Medicina Veterinária, Universidade Nove de Julho, São Paulo-SP, Brasil. \\ ${ }^{3}$ Médico Veterinário, Docente de Anatomia Animal no Departamento de Medicina Veterinária, Universidade Federal de Lavras-MG, Brasil. \\ *Autora para correspondência, E-mail:catia.massari@usp.alumni.br
}

Resumo. Esta revisão de literatura tem como objetivo descrever a anatomia do órgão de gustação dos cães, pois embora tanto se divulgue a respeito da palatabilidade aplicada à nutrição animal, ainda pouco se conhece sobre as estruturas anatômicas destinadas à percepção dos sabores dos alimentos. A língua é o órgão no qual se encontra a maioria dos receptores para o sentido da gustação, sendo que os botões gustatórios são estruturas microscópicas associadas às papilas fungiformes, foliadas e valadas da mucosa lingual canina. A via gustatória, constituída pela sequência de três tipos de neurônios, interliga os receptores linguais à porção central do sistema nervoso, possibilitando ao animal perceber e responder aos estímulos. Conclui-se que os fatores descritos no presente trabalho devem ser considerados no processo industrial de fabricação de rações, a fim de possibilitar aos cães prazer ao se alimentar, contribuindo para o bem-estar animal.

Palavras chave: Estesiologia, medicina veterinária, nutrição animal, órgãos dos sentidos, via gustatória

\section{The tasting organ of domestic dogs (Canis lupus familiaris Linnaeus, 1758)}

Abstract. This literature review aims at describing the tasting organ anatomy of dogs, because although so much is publicized about the palatability applied to animal nutrition, little is known about the anatomical structures intended for food flavors perception. The tongue is the organ in which most receptors are found for sense of taste, and the taste buds are microscopic structures associated with the fungiform, foliated and vallate papillae of the canine lingual mucosa. The gustatory pathway, constituted by a sequence of three types of neurons, connects lingual receptors to the central portion of the nervous system, allowing the animal to perceive and respond to stimuli. It is concluded that the factors described in the present work must be considered in the industrial feed manufacturing process, in order to enable dogs pleasure to feed, contributing to animal welfare.

Keywords: Esthesiology, veterinary medicine, animal nutrition, sense organs, gustatory pathway

\section{El órgano de gustación de perros domésticos (Canis lupus familiaris Linnaeus, 1758)}

Resumen. Esta revisión de literatura tiene como objetivo describir la anatomía del órgano de gustación de los perros, porque, aunque mucho se ha publicitado sobre la palatabilidad aplicada a la nutrición animal, se sabe poco sobre las estructuras anatómicas destinadas a la percepción de los sabores de los alimentos. La lengua es el órgano en que se encuentran 
la mayoría de los receptores para el sentido del gusto, y las papilas gustativas son estructuras microscópicas asociadas con las papilas fungiformes, foliadas y valadas de la mucosa lingual canina. La vía gustativa, constituida por la secuencia de tres tipos de neuronas, conecta los receptores linguales con la porción central del sistema nervioso, permitiendo que el animal perciba y responda a los estímulos. Se concluye que los factores descritos en el presente trabajo deben considerarse en el proceso de fabricación industrial de dietas, para proporcionar placer a los perros cuando se alimentan, contribuyendo al bienestar animal.

Palabras clave: Estesiología, medicina veterinaria, nutrición animal, órganos sensoriales, vía gustativa

\section{Introdução}

A história evolutiva dos canídeos é marcada pelas caçadas realizadas por matilhas, na busca de presas que variavam de coelhos a cervos. O trato digestório dos cães adaptou-se à composição de uma dieta com predominância de proteína animal, fazendo com que eles sejam classificados como "carnívoros não estritos". Estes são animais que apresentam estômago simples quanto à forma, seguido por intestino curto e pouco complexo, suficiente para a absorção de uma dieta concentrada e de fácil digestão enzimática. Atualmente, as rações tentam suprir esta demanda alimentar, e o segmento do mercado pet food vem crescendo de forma acelerada, disponibilizando produtos cada vez mais específicos (Zanatta et al., 2016).

É sabido que nem sempre um canídeo silvestre conseguia caçar com sucesso uma presa grande, por isso essa espécie muitas vezes sobrevivia com um consumo alimentar do tipo "banquete versus fome". Logo, a tendência, a partir desse padrão de comportamento ancestral, é que os cães comam exageradamente quando o alimento for abundante, ingerindo muito mais calorias do que o fisiologicamente necessário, inclusive quando há ração disponível ad libitum (Beaver, 2001). Diante disso, um dos sentidos mais importantes para os cães é a gustação. Por estar relacionado à sobrevivência em termos evolutivos no intuito de evitar a ingestão de substâncias tóxicas, esse é um dos sentidos que primeiro se estabelecem nos neonatos caninos, juntamente com o tato e o olfato (Beaver, 2001; Coren, 2005).

Este artigo tem como objetivo descrever algumas características ainda pouco exploradas do órgão de gustação dos cães domésticos, integrando a neuroanatomia à estesiologia veterinária. Isso se justifica, pois, embora tanto se divulgue a respeito da palatabilidade aplicada à nutrição animal, ainda pouca importância se dá às estruturas anatômicas destinadas à percepção dos sabores dos alimentos por essa espécie. Portanto, apresenta-se, aqui, uma revisão de literatura sobre o tema.

\section{As escolhas alimentares dos cães}

As papilas gustatórias podem ser observadas a partir do $47^{\circ}$ dia de gestação, mas é apenas nas primeiras semanas após o nascimento que a gustação se desenvolve completamente e alcança seu ápice funcional. Isso explica o fato das primeiras escolhas alimentares dos cães serem feitas por meio do sentido do olfato, ao invés do paladar (Beaver, 2001; Coren, 2005).

Para os cães, a palatabilidade dos alimentos é determinada por fatores tanto químicos quanto físicos, e baseia-se no odor, na textura, no tamanho dos pellets de ração, na temperatura e no sabor. Além disso, muitas vezes é possível relacionar as preferências alimentares caninas com as de seus tutores, bem como com o ambiente social no qual os animais estão inseridos. Quanto aos demais sentidos, sabe-se que nessa espécie a visão e a audição têm pouquíssima influência sobre a escolha dos alimentos. Portanto, quando utilizados, corantes são um atrativo apenas para os tutores, pois não interferem propriamente no paladar dos cães (Pizzato \& Domingues, 2008).

Em relação aos sabores, os cães preferem aqueles que remetem à carne (em especial a bovina, a suína e a de cordeiro) do que aos cereais. Também elegem carne enlatada em detrimento à carne fresca; preferem carne moída do que em cubos, e apreciam mais carne cozida do que crua, bem como alimentos servidos em temperatura ambiente do que gelados. Igualmente, os alimentos úmidos são mais bem aceitos quando comparados às rações secas. Contudo, e segundo a avaliação subjetiva realizada pelos tutores, eles apresentam preferências muito mais diversificadas. Entretanto, pouco se conhece sobre as 
escolhas alimentares dos cães quando se considera a idade, sexo, raça, peso e tipo de comportamento que apresentam quando estão na companhia de seus tutores. Tampouco se sabe sobre possíveis disfunções do paladar apresentadas por pacientes caninos portadores de infecções respiratórias, traumas cranioencefálicos, endocrinopatias, doença periodontal ou por aqueles que estejam recebendo quimioterapia, radioterapia e/ou apresentando algum efeito colateral causado por medicamentos (Houpt \& Smith, 1981; Nakamura \& Kurihara, 1991; Saad \& Saad, 2004).

Todavia, e apesar do conhecimento científico sobre nutrição animal ter avançado significativamente nos últimos anos (em particular sobre o papel dos nutrientes na promoção da saúde, prevenção de doenças e melhoria da qualidade de vida), não importa o quão bem formulada e produzida seja uma ração se o cão não a ingerir de maneira voluntária (Carciofi, 2007; Gouvêa, 2019; Saad \& França, 2013). Por isso, a palatabilidade se mostra como característica fundamental para a mensuração da preferência de um determinado alimento por cães, fazendo com que o consumo das rações pelos animais dependa diretamente dessa variável (Pizzato \& Domingues, 2008).

\section{O órgão de gustação}

A língua é um órgão muscular que detém a maioria dos receptores para o sentido da gustação. Sua superfície dorsal é revestida por mucosa, a qual por sua vez apresenta pequenas protrusões do epitélio, denominadas papilas, e que podem exercer função tanto mecânica quanto gustatória (Quadro 1). Aquelas que apresentam botões gustatórios estão intimamente relacionadas com a percepção do sabor (Dyce et al., 2004).

Quadro 1. Papilas linguais dos caninos domésticos.

\begin{tabular}{|ll|}
\hline Tipo de papila lingual & Características fisiológicas \\
\hline Papilas fungiformes & $\begin{array}{l}\text { Localizadas entre as papilas filiformes. São morfologicamente arredondadas e possuem } \\
\text { botões gustatórios. }\end{array}$ \\
\hline Papilas foliadas & Localizadas nas margens laterais da língua e também apresentam botões gustatórios. \\
\hline Papilas valadas & $\begin{array}{l}\text { Formam um "U" na raiz da língua, com a abertura voltada rostralmente. Contém botões } \\
\text { gustatórios. }\end{array}$ \\
\hline Papilas filiformes & $\begin{array}{l}\text { Apresentam tanto função protetora quanto mecânica. Contribuem para a distribuição dos } \\
\text { alimentos na superfície da língua, assim como para promover o contato do bolo alimentar } \\
\text { com a saliva. Não possuem botões gustatórios. }\end{array}$ \\
\hline Papilas marginais & $\begin{array}{l}\text { Também denominadas papilas rendadas, estão presentes apenas no período neonatal } \\
\text { (durante a primeira quinzena de vida). Auxiliam a acomodação da língua do neonato sob } \\
\text { a mama da cadela para sucção do leite. }\end{array}$ \\
\hline
\end{tabular}

Fonte: adaptado de Sisson et al. (1986).

Existem receptores gustatórios na lâmina basal e no epitélio da língua, palato mole, faringe e laringe (epiglote), os quais são estimulados pelas substâncias químicas do alimento que entram em contato com a cavidade oral (Prada, 2014).

Os botões gustatórios são estruturas microscópicas, associadas às papilas fungiformes, foliadas e valadas da língua. São formados por um conjunto de células de sustentação, associadas àquelas receptoras de sabor, as quais possuem núcleos alongados e microvilosidades que se projetam para o interior dos poros gustatórios (Figura 1 e 2). Estes botões, por sua vez, são estimulados pelas soluções (partículas alimentares embebidas em saliva) que entram em contato com a língua e, na sequência, sensibilizam as células receptoras (Dvoryanchikov et al., 2007; Sisson et al., 1986).

Para que o animal distinga o sabor de cada alimento, é necessário que este se encontre em solução, condição necessária para penetrar no poro gustatório e posteriormente estabelecer contato com os "pelos gustatórios" (microfibras), os quais estão imediatamente ligados à fibra nervosa sensorial na célula receptora. Logo, a secreção das glândulas salivares é fundamental para propiciar a dissolução do conteúdo alimentar para que este atue de forma eficiente nos botões gustatórios. 


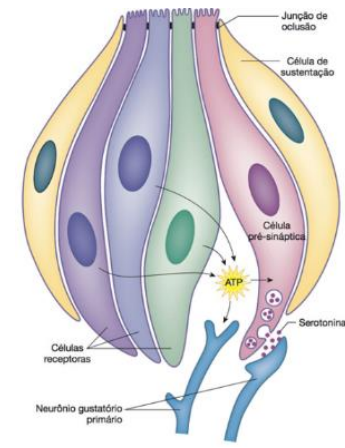

Figura 1. Representação esquemática de um botão gustatório, o qual é constituído por células gustatórias e células de sustentação, unidas na superfície apical por meio de junções de oclusão. Na superfície basal, os ligantes gustatórios geram sinais por meio de canais de cálcio, dependentes de voltagem e liberadores de ATP ou de serotonina, estimulando o neurônio primário. Fonte: adaptado de Silverthorn (2010).

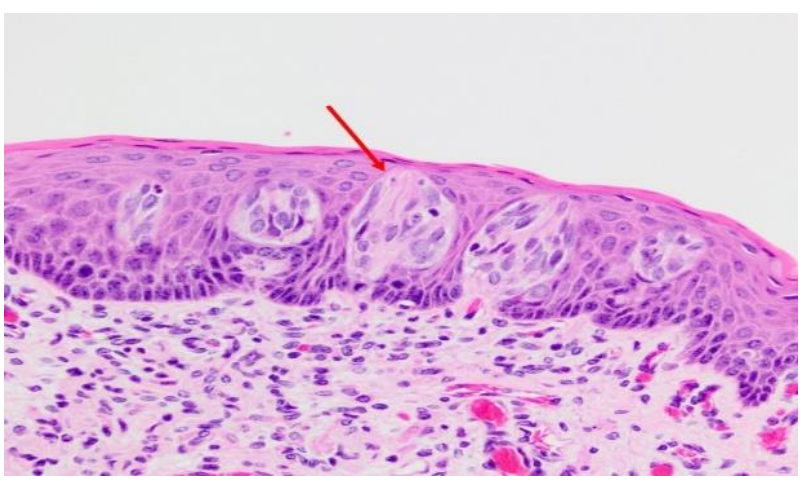

Figura 2. Lâmina histológica da superfície da língua de alpaca, com aglomerados de células quimiorreceptoras especializadas. A seta vermelha indica um botão gustatório, em cuja superfície apical é possível observar o poro gustatório. Fonte: adaptado de Jennings et al. (2017).

\section{As vias gustatórias}

No que se refere às sensações gustatórias potencialmente perceptíveis pelos cães, as principais são a doçura e a salinidade (ambas captadas pelos botões gustatórios presentes nas papilas fungiformes localizadas nos $2 / 3$ rostrais da língua), embora a acidez - captada pelos botões gustatórios das papilas valadas e foliadas, situadas no $1 / 3$ caudal da língua - seja também relevante (Sisson et al., 1986). O trajeto para a interpretação dessas impressões, e de outras sensações captadas pela língua, a ser processada na porção central do sistema nervoso, envolve três vias gustatórias (aferentes), compostas por nervos responsáveis por receberem os estímulos e os conduzirem até o encéfalo.

As fibras nervosas responsáveis pela percepção gustatória proveniente dos $2 / 3$ rostrais da língua entram na formação dos ramos linguais (derivados da divisão mandibular do $\mathrm{V}$ par nervos cranianos nervo trigêmeo) e do nervo corda do tímpano. Em seguida, fazem sinapse no gânglio geniculado do componente intermédio do VII par nervos cranianos (nervo intermediofacial) e penetram no bulbo ou medula oblonga, a porção mais caudal do tronco encefálico, este constituído também pela ponte e mesencéfalo (Cosenza, 2000; Sisson et al., 1986). Já as fibras provenientes do 1/3 caudal da língua, participam da composição do IX par de nervos cranianos (nervo glossofaríngeo), o qual também faz conexão na medula oblonga. Por fim, na região da epiglote, os poucos receptores gustatórios aí localizados integram o X par de nervos cranianos (nervo vago) que, igualmente, se conecta ao tronco encefálico.

O sétimo, o nono e o décimo pares de nervos cranianos são considerados de natureza mista, por possuírem tanto fibras sensitivas (aferentes) quanto motoras (eferentes). No caso do VII par, a porção facial tem função motora, enquanto que o componente intermédio é sensitivo, sendo o principal responsável pela sensação de paladar presente nos $2 / 3$ rostrais da língua. Por sua vez, o nervo glossofaríngeo é composto também por fibras aferentes que conduzem a percepção de paladar captada no $1 / 3$ caudal da língua. Já o nervo vago possui fibras com função semelhante, as quais são responsáveis por conduzirem a sensação de paladar oriunda da orofaringe (Noureldine, 2019).

Os corpos neuronais das referidas vias sensitivas desses três pares de nervos cranianos situam-se nos respectivos gânglios, e os axônios penetram no tronco encefálico, no qual estabelecem sinapses com neurônios presentes na porção rostral do núcleo do trato solitário. Neste, há fibras que se dirigem para ambos os antímeros do tálamo. Na sequência, os neurônios talâmicos migram para a área cortical responsável pela gustação, onde a informação é finalmente processada (Cosenza, 2000). Portanto, é através desse trajeto que os receptores gustatórios geram impulsos nervosos que chegam ao cérebro para serem interpretados como sabores específicos (Colville, 2011). 
Todos os neurônios sensitivos ou aferentes típicos são classificados morfologicamente como pseudounipolares ou bipolares e apresentam, via de regra, dois prolongamentos a partir do corpo celular: um que se origina nos receptores sensitivos presentes na língua, e outro que se destina à porção central do sistema nervoso (igura 3).
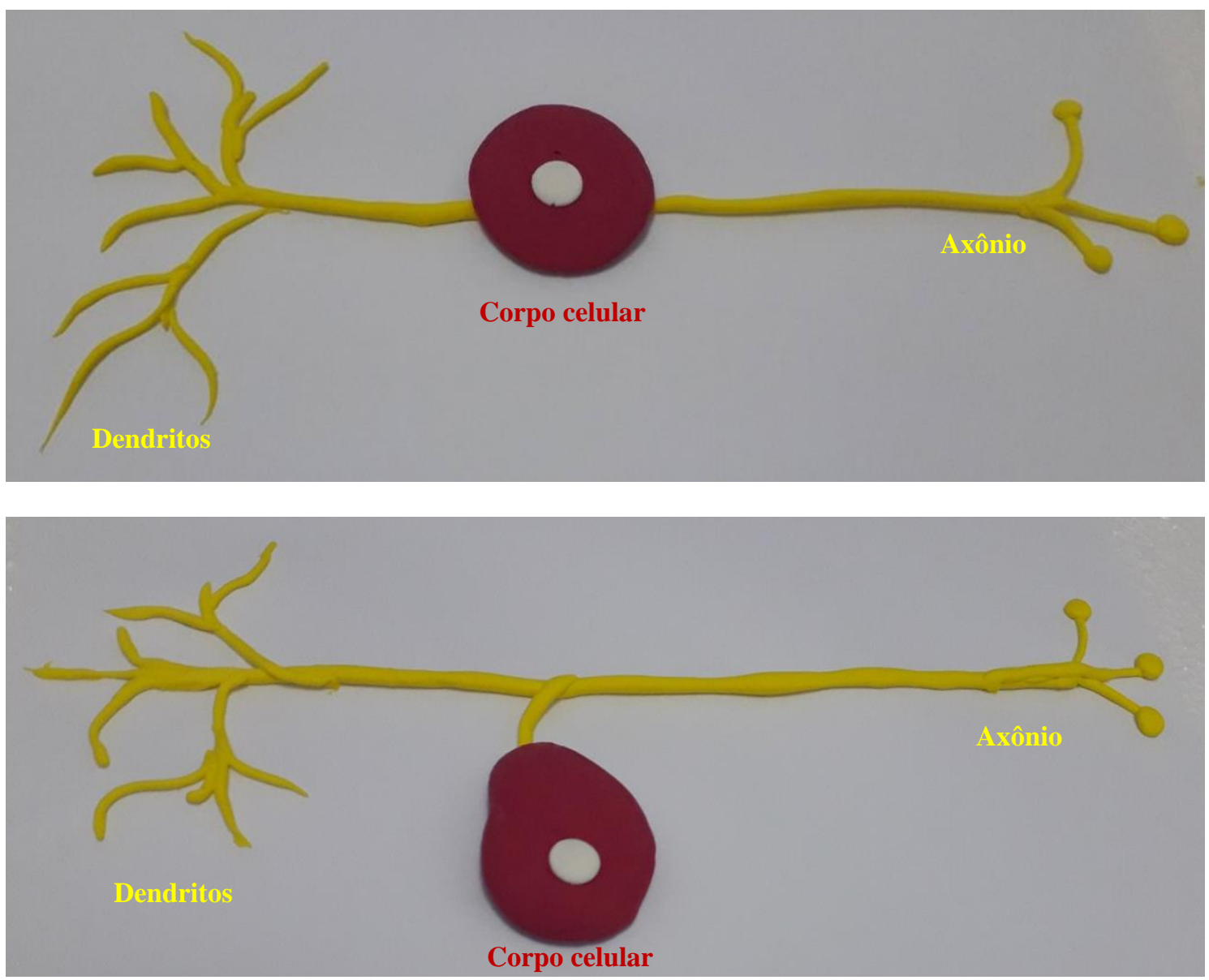

Figura 3. Representação de neurônios bipolar (superior) pseudounipolar (inferior) por meio da técnica de modelagem com massa acrílica, como método complementar ao ensino de neuroanatomia microscópica.

Diante do exposto, conclui-se que a via gustatória é constituída pela sequência de neurônios aferentes, aqui didaticamente denominados primário, secundário e terciário (Quadro 2).

Quadro 2. Vias neurais envolvidas no sentido da gustação do canino doméstico.

\begin{tabular}{|c|c|}
\hline Neurônio & Características anatômicas \\
\hline Primário & $\begin{array}{l}\text { O pericário localiza-se nos gânglios: geniculado (VII par); distal do nervo glossofaríngeo (IX), e distal } \\
\text { do nervo vago (X). O prolongamento distal parte dos respectivos receptores gustatórios, enquanto que o } \\
\text { proximal penetra no tronco encefálico. Neste segmento do encéfalo, e após curto trajeto pelo trato } \\
\text { solitário, faz sinapse com o neurônio secundário. }\end{array}$ \\
\hline Secundário & $\begin{array}{l}\text { O corpo está no núcleo do trato solitário, de onde partem as fibras solitariotalâmicas. Nos animais, as } \\
\text { vias de projeção da sensibilidade gustatória para centros superiores não estão bem definidas, admitindo- } \\
\text { se que existam numerosas eferências a estruturas do sistema límbico e áreas do córtex cerebral } \\
\text { relacionadas à memória, o que se reveste de grande importância em termos comportamentais. Parte das } \\
\text { fibras solitariotalâmicas chega a ambos os antímeros talâmicos. Daí se originam as fibras que formam o } \\
\text { último segmento da via gustatória, as quais se dirigem até a área gustatória do córtex cerebral, esta } \\
\text { adjacente à parte da área somestésica referente à língua. }\end{array}$ \\
\hline Terciário & $\begin{array}{l}\text { O pericário encontra-se no grupo ventral dos núcleos talâmicos, sendo que os axônios que daí partem } \\
\text { projetam-se no córtex cerebral, próximo à área somestésica primária para a face. A área gustatória do } \\
\text { córtex cerebral em animais localiza-se, também, próxima à área somestésica relacionada à cabeça. }\end{array}$ \\
\hline
\end{tabular}

Fonte: adaptado de Prada (2014). 
Assim sendo, a via da gustação, exclusivamente sensitiva, é, portanto, aferente, sendo constituída por uma cadeia de neurônios que interliga as terminações nervosas - localizadas nos receptores dos botões gustatórios - ao córtex cerebral. Nesse trajeto ocorre, no tálamo, a transmissão desses impulsos nervosos. Este órgão, por sua vez, é parte do diencéfalo e constituído por duas massas ovoides, predominantemente constituída de substância cinzenta, a qual se organiza sob a forma de núcleos (Figura 4).

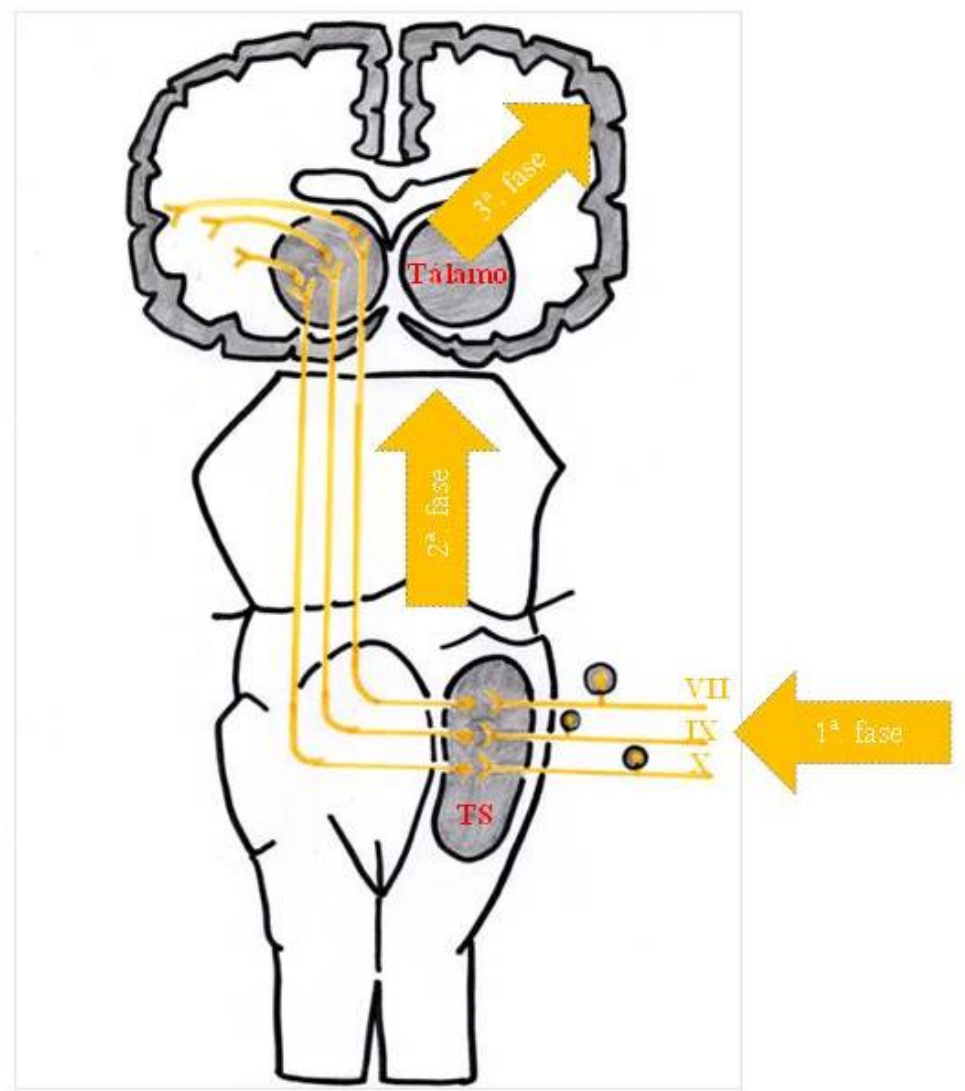

Figura 4. Representação parcial do trajeto neuronal da via gustatória. $1^{a}$ fase: os neurônios primários de três nervos cranianos (VII, IX e X) possuem fibras periféricas oriundas dos receptores gustatórios da língua, e prolongamentos centrais que adentram no tronco encefálico (núcleo do trato solitário - TS). $2^{a}$ fase: neurônios secundários formam as fibras solitariotalâmicas, as quais partem do núcleo do trato solitário e se dirigem ao tálamo. $3^{a}$ fase: deste último se originam os neurônios terciários, os quais se destinam à região gustatória do córtex cerebral. Fonte: (Prada, 2014).

Em virtude da existência de complexa rede de interação entre o sistema nervoso e outras percepções que subsidiam o processo estímulo-resposta nos cães, não é possível afirmar com exatidão o real sabor que cada animal identifica, em resposta aos estímulos percebidos, decorrentes do contato entre o alimento e os receptores gustatórios. Trata-se de um intrincado processo da relação cérebro-mente nos animais domésticos. Por isso, entre outras limitações da pesquisa clínica, não é tão simples avaliar a função sensorial dos cães, já que a experiência de cada ser é única, subjetiva e intransferível a outro modelo experimental Prada (2014).

Como os testes comuns de palatabilidade, em tese, permitem avaliar a preferência alimentar, à princípio, mais por meio da olfação do que propriamente pela gustação, sugere-se o emprego da técnica de gustometria comportamental como exame complementar para o diagnóstico de distúrbios do paladar. Porém, é imprescindível que o protocolo desse teste seja ajustado e validado para a espécie canina, com a finalidade de se evitar interpretações equivocadas e de se obter efetiva aplicabilidade na clínica médica de pequenos animais (Myers, 1991).

Certamente, o órgão de gustação dos cães pode interpretar e responder a um vasto repertório de biomoléculas, como, por exemplo, açúcares, sais, ácidos, aminoácidos e a uma gama de substâncias 
tóxicas (geralmente amargas). Até o século XX, acreditava-se, de maneira errônea, que a língua era rigorosamente compartimentalizada no que se refere à percepção gustatória. Inclusive, muitos testes neurológicos acabaram sendo desenvolvidos baseados na falsa premissa de que botões gustatórios, específicos para cada sabor, estariam concentrados em regiões específicas da língua. No entanto, atualmente, sabe-se que estas estruturas se encontram distribuídas aleatoriamente por todo o dorso do órgão e pelo palato. Assim, o doce, o amargo e o umami são percebidos por meio de receptores de membrana e, em contrapartida, o salgado e o ácido dependem de canais iônicos especializados de $\mathrm{Na}^{2+}$ e $\mathrm{H}^{+}$, presentes nas células dos botões gustatórios. Todavia, há necessidade de mais pesquisas sobre os mecanismos moleculares responsáveis pelo paladar canino (Faber, 2006; Kumazawa et al., 1991).

\section{Considerações finais}

A capacidade de reconhecimento dos diversos sabores pelos cães deve-se à combinação entre os sentidos da gustação e da olfação, além de outras possíveis sensações mediadas pelo sistema somatossensorial. Em suma, isso permite que os animais obtenham informações valiosas sobre a natureza e a qualidade dos alimentos disponíveis, optem por alimentos mais palatáveis e evitem possíveis riscos de intoxicação alimentar e/ou de morte.

Devido ao fato da percepção gustatória dos cães resultar de intrincada interação entre vários estímulos sensoriais concomitantes por eles percebidos e a constituição físico-química dos alimentos, conclui-se que todos os fatores descritos no presente trabalho devem ser considerados no processo industrial empregado na fabricação de rações para essa espécie, assim como na escolha dos ingredientes e palatabilizantes a serem utilizados.

\section{Referências}

Beaver, B. V. (2001). Comportamento canino: um guia para veterinários. Roca.

Carciofi, A. C. (2007). Métodos para estudo das respostas metabólicas de cães e gatos a diferentes alimentos. Revista Brasileira de Zootecnia, 36, 235-249. DOI: https://doi.org/10.1590/s1516$\underline{35982007001000022}$

Colville, T. (2011). Anatomia e fisiologia clínica para medicina veterinária. Elsevier Brasil.

Coren, S. (2005). How dogs think: Understanding the canine mind. Simon and Schuster.

Cosenza, R. M. (2000). Fundamentos de neuroanatomia. Grupo Guanabara Koogan.

Dvoryanchikov, G., Tomchik, S. M., \& Chaudhari, N. (2007). Biogenic amine synthesis and uptake in rodent taste buds. Journal of Comparative Neurology, 505(3), 302-313. DOI: https://doi.org/10.1002/cne.21494

Dyce, K. M., Wensing, C. J. G., \& Sack, W. O. (2004). Tratado de anatomia veterinária. Elsevier Brasil.

Faber, J. (2006). Avanços na compreensão do paladar. Revista Dental Press de Ortodontia e Ortopedia Facial, 11(1), 14. DOI: https://doi.org/10.1590/s1415-54192006000100003

Gouvêa, F. de L. (2019). Alimentos convencionais e a tendência a alimentos alternativos para animais de companhia: uma visão sobre o perfil de tutores e a escolha de alimentos para cães e gatos.

Houpt, K. A., \& Smith, S. L. (1981). Taste preferences and their relation to obesity in dogs and cats. The Canadian Veterinary Journal, 22(4), 77-85.

Jennings, R., Premanandan, C., Ciancolo, R., Wilkie, D., Wong, A., \& Kendzioski, J. (2017). Veterinary histology. Ohio State University Libraries.

Kumazawa, T., Nakamura, M., \& Kurihara, K. (1991). Canine taste nerve responses to umami substances. Physiology \& Behavior, 49(5), 875-881. DOI: https://doi.org/10.1016/00319384(91)90197-V

Myers, L. J. (1991). Use of innate behaviors to evaluate sensory function in the dog. Veterinary Clinics of North America: Small Animal Practice, 21(2), 389-399. DOI: https://doi.org/10.1016/s01955616(91)50040-1

Nakamura, M., \& Kurihara, K. (1991). Differential temperature dependence of taste nerve responses to various taste stimuli in dogs and rats. American Journal of Physiology-Regulatory, Integrative and 
Comparative Physiology, 261(6), 1402-1408. DOI: https://doi.org/10.1152/ajpregu.1991.261.6.r1402

Noureldine, M. H. A. (2019). Fundamentos de Neuroanatomia: um guia clínico. Elselvier Saunders.

Pizzato, D. A., \& Domingues, J. L. (2008). Palatabilidade de alimentos para cães. Revista Eletrônica Nutritime, 5(2), 504-511.

Prada, I. (2014). Neuroanatomia funcional em medicina veterinária. Terra Molhada.

Saad, F M O B, \& Saad, C. E. P. (2004). História evolutiva na alimentação e controle de consumo dos cães e gatos. Universidade Fedeeral de Lavras.

Saad, Flávia Maria Oliveira Borges, \& França, J. (2013). Novas alternativas alimentares para cães e gatos:-Alimentos livres de grãos (grain free). Congresso Brasileiro de Zootecnia.

Silverthorn, D. U. (2010). Fisiologia humana: uma abordagem integrada. Artmed editora.

Sisson, S., Grossman, J. D., \& Getty, R. (1986). Anatomia dos animais domésticos. Interamericana.

Zanatta, C. P., Félix, A. P., Oliveira, S. G., \& Maiorka, A. (2016). Factors that regulate food intake and preference in dogs. Scientia Agraria Paranaensis, 15(2), 109-114. DOI: https://doi.org/10.18188/1983-1471/sap.v15n2p109-114.

\section{Histórico do artigo:}

Recebido: 9 de agosto de 2020 .

Aprovado: 31 de agosto de 2020 .

Disponível online: 26 de janeiro de 2021.
Licenciamento: Este artigo é publicado na modalidade Acesso Aberto sob a licença Creative Commons Atribuição 4.0 (CC-BY 4.0), a qual permite uso irrestrito, distribuição, reprodução em qualquer meio, desde que o autor e a fonte sejam devidamente creditados. 